\title{
User Interaction with Inverted-F Antennas Integrated into Laptop PCMCIA Cards
}

\author{
Jerzy GUTERMAN ${ }^{1}$, António A. MOREIRA ${ }^{1}$, Custódio PEIXEIRO ${ }^{1}$, Yahya RAHMAT-SAMII ${ }^{2}$ \\ ${ }^{1}$ Instituto de Telecomunicações, Instituto Superior Técnico, Av. Rovisco Pais 1, 1049-001 Lisboa, Portugal \\ ${ }^{2}$ University of California, Los Angeles, CA 90095-1594 USA
}

\{jerzy.guterman, antonio.moreira, custodio.peixeiro\}@1x.it.pt,rahmat@ee.ucla.edu

\begin{abstract}
This paper evaluates the overall laptop integration effects on the performance of commercial $2.4 \mathrm{GHz}$ Inverted-F antennas built into PCMCIA cards. A generic laptop model is used to represent the antenna housing effects while an anatomical shape homogenous human model is used to estimate the electromagnetic interaction between the antenna and the user. The antenna performance is evaluated for different card locations in terms of reflection coefficient, far-field gain pattern and radiation efficiency. The human exposure to EM radiation is analyzed in terms of Specific Absorption Rate.
\end{abstract}

\section{Keywords}

Laptop antennas, inverted-F antennas, electromagnetic human interaction, wireless communications.

\section{Introduction}

In the age of 'information society' laptop computers are inherently associated with wireless connectivity. The vast majority of today's laptops communicate with peripheral devices (Wireless Personal Area Networks, WPAN) and other computers (Wireless Local Area Networks, WLAN) via radio technologies. Moreover, the integration of cellular network radios into some laptops gives the user access to the Internet in areas not covered by WLANs. An enormous progress in integrated circuits technology enabled manufacturers to miniaturize wireless interface electronics and easily integrate them within relatively large laptop terminals (when compared to handsets or PDAs). The overall performance of this lumped block can generally be platform-independent. On the other hand laptop antennas, even when denoted as compact, are always interacting with the electromagnetic field surrounding the PC, therefore its operation depends on the laptop structure as well as on the nearby environment.

The nearest vicinity of the antenna is constituted by the laptop structure itself, and its influence on the radiator performance plays a key role. Laptop housing effects have been already investigated for both plug-in [1] and built-in
[2] wireless interfaces. When a typical scenario of laptop operation is considered, the user makes indispensably part of the antenna neighborhood. It has already been shown that for handset-mounted antennas the presence of nearby biological tissue is a key consideration [3]. The electromagnetic interaction between the antenna and the human also affects the overall system performance and should be evaluated. The interaction between a side mounted laptop $5.2 \mathrm{GHz}$ sleeve dipole antenna and the operator has been already investigated in [4].

In this paper we highlight the antenna - environment interaction for a $2.4 \mathrm{GHz}$ inverted-F antenna (IFA) integrated into a plug-in interface. In order to clearly identify the laptop housing effects and the operator influence, the PCMCIA antenna performance is compared for three scenarios: (i) freestanding card, (ii) card + laptop and (iii) card + laptop + user. The last scenario (iii) corresponds to the typical laptop antenna operation situation and real antenna in-use performance. The exposure of the laptop user to EM radiation is also evaluated.

\section{Antenna and Environment Modeling}

The present analysis is based on 3D full-wave simulations performed with CST software package.

\subsection{Antenna Element Modeling}

Although most modern laptop computers are equipped with internal wireless interfaces, external radios housed in PCMCIA cards and miniature USB dongles are still very common. The IFA element is one of the most popular integrated antennas for plug-in interfaces due to its planar structure, small size and easy integration on a circuit board [5]. It consists of a quarter wavelength arm, placed parallel to the ground plane edge and shorted in one end (Fig. 1). Essentially an IFA is half the size of the traditional $\lambda / 2$ slot antenna and their mechanisms of operation are analogous. By moving the feeding stub from the shorting stub to the open slot end, the IFA input impedance changes from low to high values. IFAs have also been successfully 
used for laptop built-in antennas [6]. In this study an IFA element operating in the ISM $2.4 \mathrm{GHz}$ band has been used, see Fig. 1.

\subsection{Laptop Modeling}

In order to minimize radiation from today's high speed electronics, manufacturers are forced to use conducting laptop covers or thin metallic layers just inside the laptop casing [6]. Such a structure as a whole can be fairly approximated by a several wavelengths in size (at WLAN/WPAN frequencies) metallic box. The main effects are the introduction of reflection and blockage of the laptop antenna radiation. In this study the following laptop model has been used:

- keyboard base: $295 \times 260 \times 25\left[\mathrm{~mm}^{3}\right]$ PEC box (Fig. 1),

- lid: $295 \times 225 \times 5\left[\mathrm{~mm}^{3}\right]$ PEC box, mounted perpendicularly to the keyboard base (Fig. 1),

- PCMCIA card: $102 \times 50 \times 5\left[\mathrm{~mm}^{3}\right]$ PEC box.

Two typical PCMCIA card positions have been considered: inserted into the back card slot $(\mathrm{Ba})$ and into the front card slot (Fr), see Fig. 2.

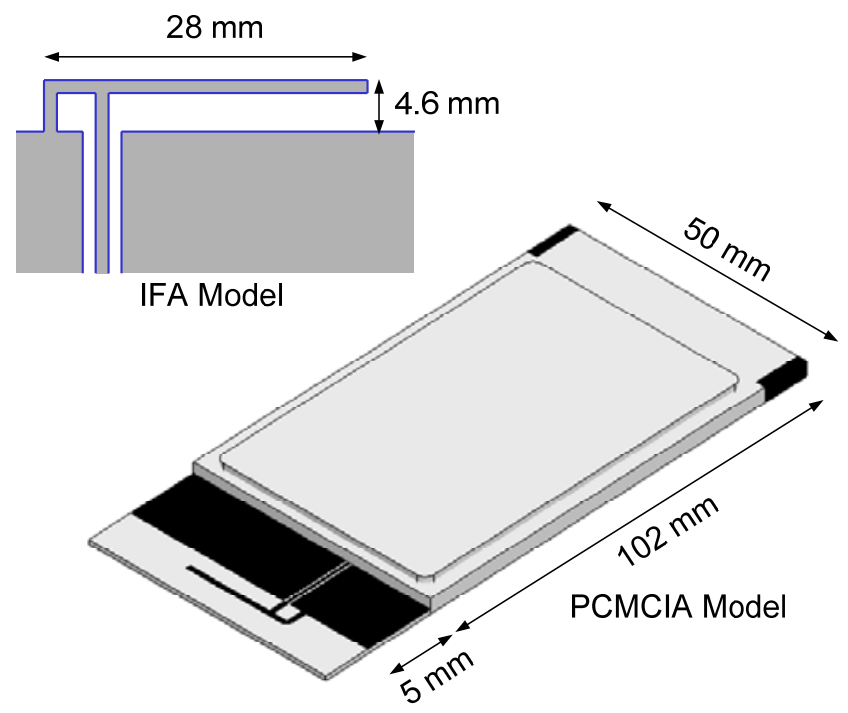

Fig. 1. IFA element model housed in a PCMCIA card. The antenna part protruding from the PC is usually enclosed in a plastic case.

\subsection{Human Modeling}

A human body model based on an anatomical mannequin, corresponding to a $177 \mathrm{~cm}$ tall, $72 \mathrm{~kg}$ in weight male, generated by Poser software tool, has been used. A typical typing posture (Fig. 2) has been introduced. Since only the external shapes and sizes are used, the generated model is homogeneous. Dielectric material of relative permittivity $\varepsilon_{\mathrm{r}}=40$, dielectric loss tangent $\tan \delta=0.157$ and mass den- sity $\rho=1000 \mathrm{~kg} / \mathrm{m}^{3}$ has been used to simulate the biological tissue at $2.44 \mathrm{GHz}$.

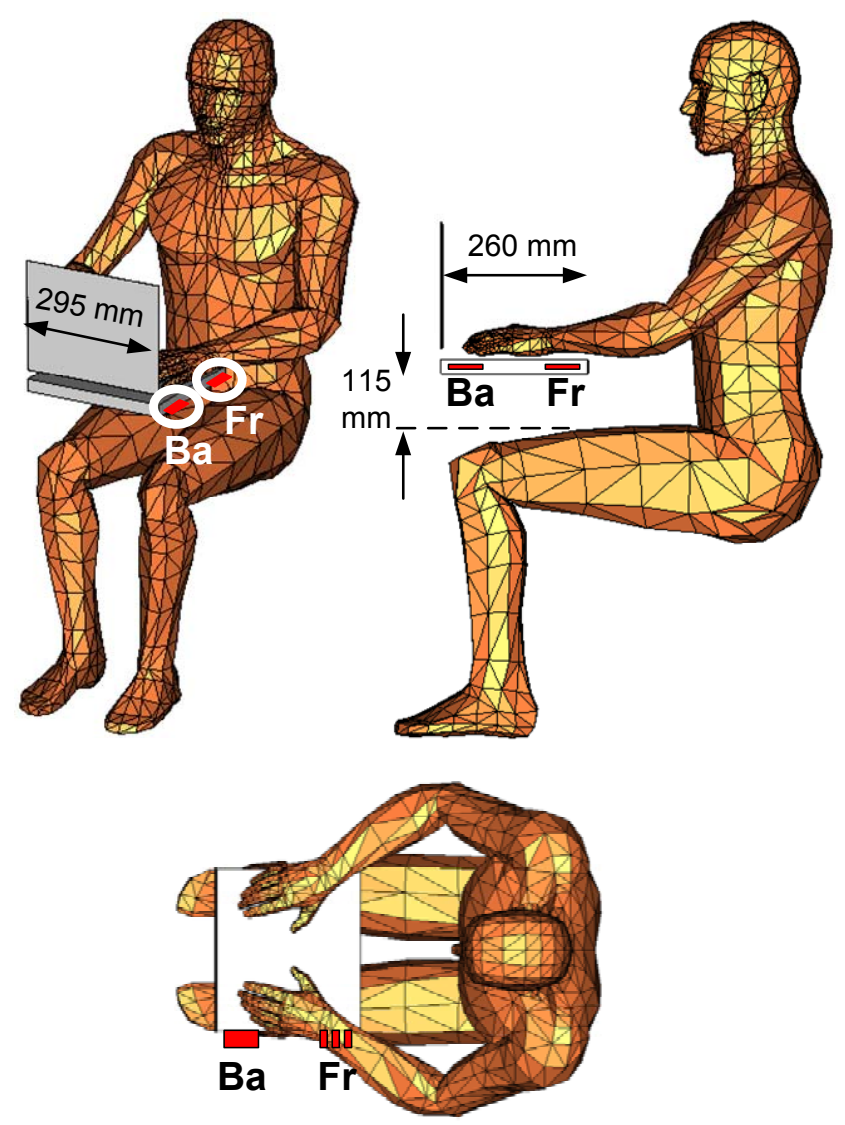

Fig. 2. Perspective, side, and top views of the modeled laptop and user: $\mathrm{Ba}$ - back slot location, $\mathrm{Fr}$ - front slot location.

\section{Antenna Performance}

The antenna performance has been evaluated for three scenarios: (i) freestanding PCMCIA card, (ii) card + laptop, and (iii) card + laptop + user. In addition, the two card locations indicated in Fig. 2 have been considered. The minimum distance between the biological tissue and the IFA arm is $33 \mathrm{~mm}$ for the back location and $35 \mathrm{~mm}$ for the front location.

The comparison of the input reflection coefficient for the front (Fr) card location three scenarios is presented in Fig. 3. The achieved impedance frequency bands for all scenarios are resumed in Tab. 1. Almost the same input reflection coefficient results have been obtained for the back $(\mathrm{Ba})$ card location. The laptop housing has a strong influence on the antenna matching because it disturbs the electromagnetic fields in the very close vicinity of the radiator. As the exact card location is not the same for different laptop manufacturers, sufficient bandwidth margins have to be provided to overcome some potential detuning. In the simulated scenarios the presence of the operator has shown a minor influence on $S_{11}$. 
The total gain far-field radiation pattern of an IFA attached to a freestanding PCMCIA card is presented in Fig. 4 (first row) [3]. In this scenario a significant contribution to the radiation comes from the card ground plane, which behaves as a one wavelength dipole (notice the butterfly horizontal plane pattern). When the card is inserted into the PC (Fig. 4, rows 2 and 4) the far-field pattern is notably changed. The corner reflector formed by the keyboard and the screen setup causes enhanced radiation towards the screen front left side (see 3D patterns in Fig. 4 and max. gain values in Tab. 1) while some screen shadow areas are created for the front card location (see H-plane pattern around $120^{\circ}$ ) [1].

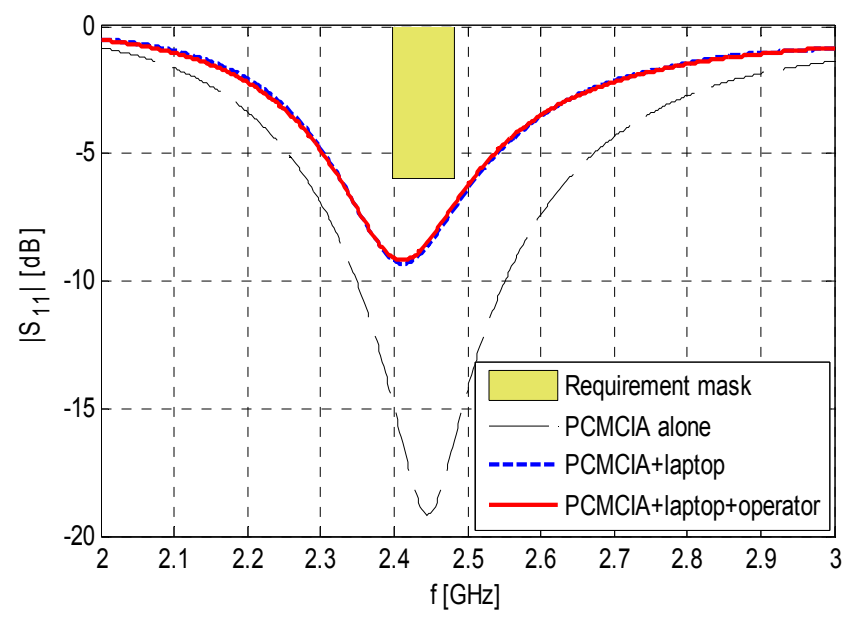

Fig. 3. Antenna reflection coefficient for PCMCIA card front slot location.

\begin{tabular}{|c|c|c|}
\hline Parameter & Back location & Front location \\
\hline $\begin{array}{c}\left|\mathrm{S}_{11}\right| \leq \text { - } 6 \mathrm{~dB} \text { frequency } \\
\text { band [GHz] } \\
\text { (card alone) }\end{array}$ & \multicolumn{2}{|c|}{$\begin{array}{l}2.280-2.637 \\
B W=0.356\end{array}$} \\
\hline $\begin{array}{c}\left|\mathrm{S}_{11}\right| \leq \text { - } 6 \mathrm{~dB} \text { frequency } \\
\text { band [GHz] } \\
\text { (card + laptop) }\end{array}$ & $\begin{array}{c}2.325-2.512 \\
B W=0.187\end{array}$ & $\begin{array}{c}2.326-2.510 \\
B W=0.184\end{array}$ \\
\hline $\begin{array}{c}\left|\mathrm{S}_{11}\right| \leq \text { - } 6 \mathrm{~dB} \text { frequency } \\
\text { band [GHz] } \\
\text { (card + laptop + user) }\end{array}$ & $\begin{array}{l}2.326-2.512 \\
B W=0.186\end{array}$ & $\begin{array}{c}2.326-2.506 \\
B W=0.180\end{array}$ \\
\hline $\begin{array}{l}\text { Maximum gain }[\mathrm{dBi}] \\
\quad \text { (card alone) }\end{array}$ & \multicolumn{2}{|c|}{3.04} \\
\hline $\begin{array}{l}\text { Maximum gain [dBi] } \\
\text { (card + laptop) }\end{array}$ & 6.76 & 5.47 \\
\hline $\begin{array}{l}\text { Maximum gain [dBi] } \\
\text { (card + laptop + user) }\end{array}$ & 5.14 & 2.22 \\
\hline $\begin{array}{l}\text { Radiation efficiency } \\
\eta_{\mathrm{r}}[\%]\end{array}$ & 77 & 44 \\
\hline Max SAR location & $\begin{array}{l}\text { left palm little } \\
\text { finger }\end{array}$ & left wrist \\
\hline $\begin{array}{c}\text { Max SAR [W/kg] } \\
10 \mathrm{~g} / 1 \mathrm{~g}\end{array}$ & $0.771 / 1.288$ & $2.151 / 2.932$ \\
\hline
\end{tabular}

Tab. 1. Summary of simulation results.
The user presence causes a significant change in the radiation pattern (Fig. 4, rows 3 and 5). For both antenna locations a strong human torso shadow effect (up to $15 \mathrm{~dB}$ ) is observed. Moreover, for the front card location, the user wrist practically covers the antenna leading to reduced upward radiation (as much as $10 \mathrm{~dB}$ ).

The close proximity of the lossy biological tissue also causes antenna radiation efficiency degradation. The models used in the numerical simulation consider the antenna element structure and laptop housing composed solely of PEC. Therefore, as no lossy dielectric elements are used, the entire power absorbed by the system $P_{\text {abs }}$ is absorbed solely by the human body. The radiation efficiency of the laptop + user system is defined as

$$
\eta_{r}=\frac{P_{r a d}}{P_{r a d}+P_{a b s}}=\frac{P_{r a d}}{P_{a c c}}
$$

where $P_{\text {rad }}$ is the power radiated to the far-field region, $P_{a c c}$ is the antenna accepted power and $P_{a b s}$ is the power absorbed by the human body.

The antenna radiation efficiency calculated according to equation (1) is presented in row eight of Tab. 1. For the card front location the human body absorbs $56 \%$ of the energy radiated by the antenna, whereas for back card location the estimated value is $23 \%$.

\section{SAR Evaluation}

The exposure of human tissue to EM radiation has been evaluated in terms of Specific Absorption Rate (SAR) for an antenna output power $1 \mathrm{~W}$ (peak). Fig. 5 presents the $10 \mathrm{~g}$ averaged SAR distribution on the human body surface and the maximum 3D SAR values are given in Tab. 1. The user left arm is strongly illuminated by the antenna, and the peak SAR values occur in the part of the hand closest to the radiator. Significant SAR values (peak/10) occur in the user's leg and abdomen (especially for front card location). It should be noticed that the given values of SAR are normalized to $1 \mathrm{~W}$ peak antenna output power, while typically a WLAN antenna radiates about $10 \mathrm{~mW}$. Therefore, for a real operating system, a maximum SAR $(10 \mathrm{~g})$ of $0.022 \mathrm{~W} / \mathrm{kg}$ is expected, which is almost a hundred times lower than the European safety limit $(2 \mathrm{~W} / \mathrm{kg})$ [7].

It should be noted, however, that other wireless laptop interfaces, like cellular modems or WiMAX radios, can work with much higher power levels; also, the properties of the human tissue are frequency dependent. Finally, the simplified homogenous human model does not take into account different electromagnetic properties of different human tissues and provides only an estimation of the absorbed energy. 


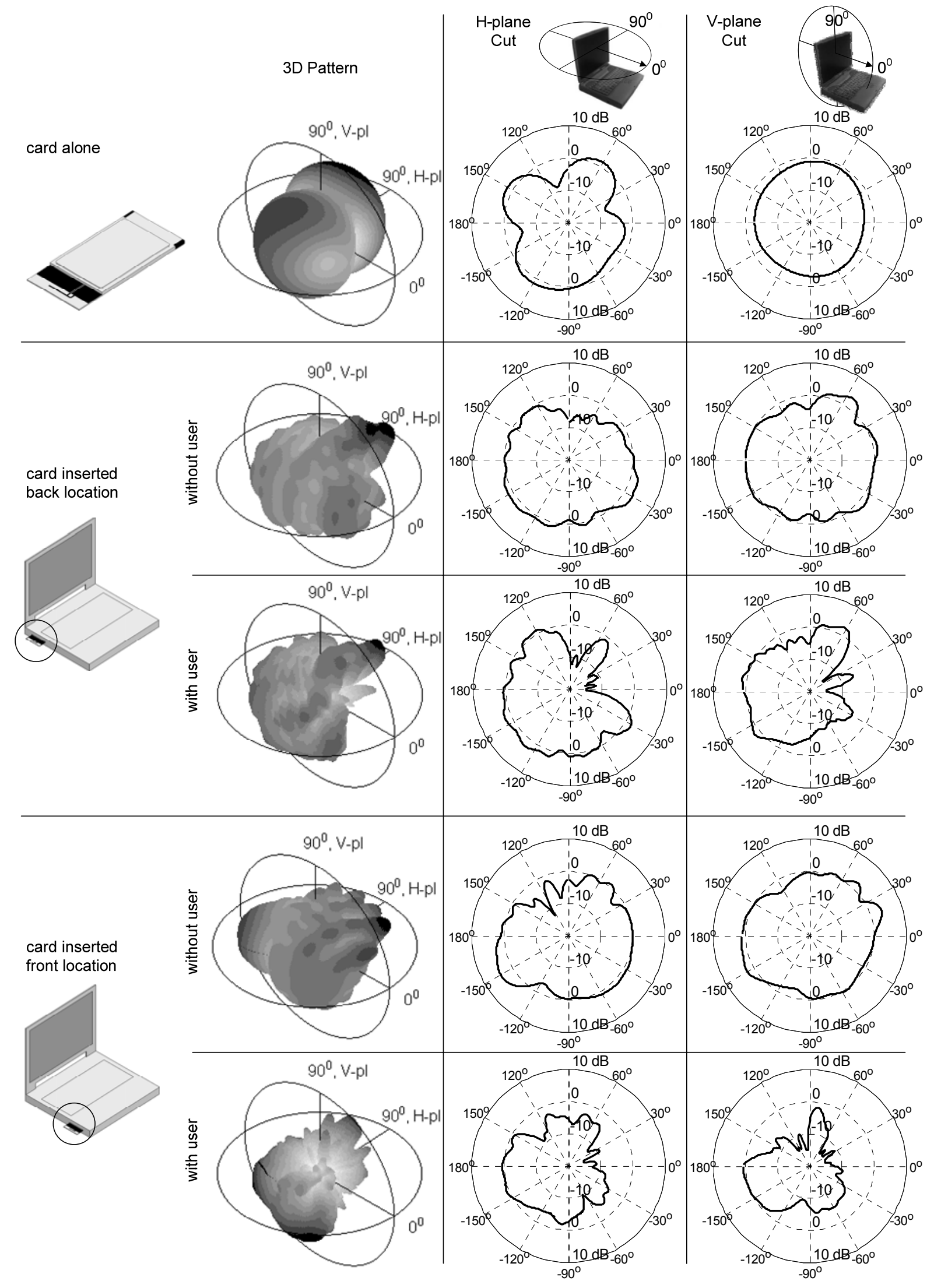

Fig. 4. IFA element mounted on a PCMCIA card: computed far field gain pattern at $2.44 \mathrm{GHz}$ for different scenarios. 


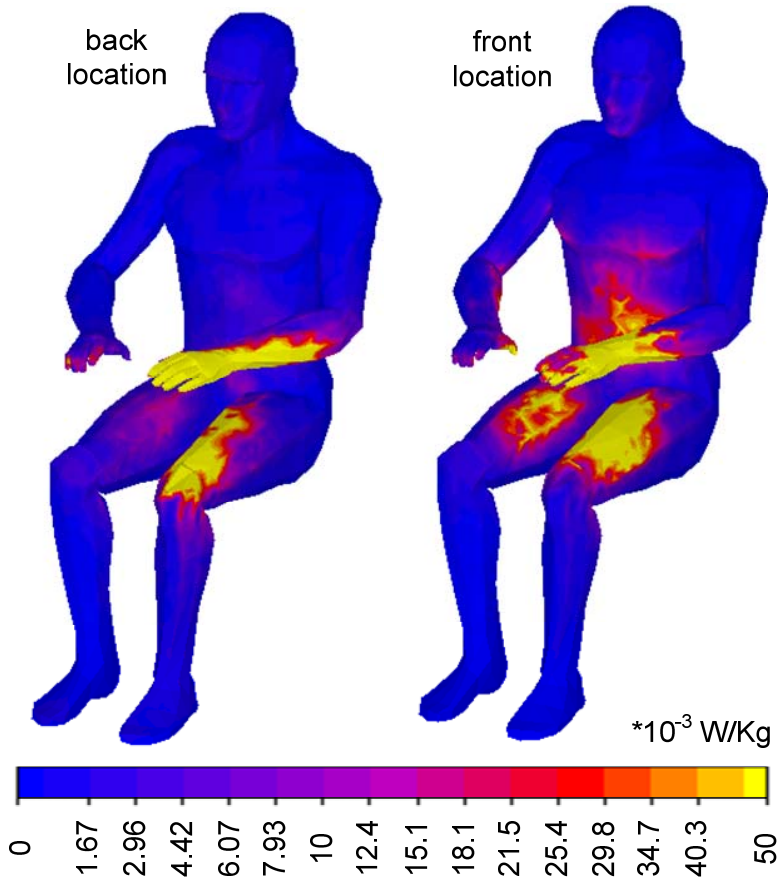

Fig. 5. SAR (averaged over $10 \mathrm{~g}$ of tissue) distribution on the human body surface, $\mathrm{f}=2.44 \mathrm{GHz}$.

\section{Conclusions and Future Work}

A $2.4 \mathrm{GHz}$ inverted-F antenna housed in a PCMCIA card has been investigated from the perspective of a laptop application. Three scenarios have been analyzed in the numerical simulations: (i) a standalone wireless card, (ii) a card inserted into a laptop and (iii) a laptop/card setup operated by the user. In the last case (iii) an anatomical shape homogenous human model has been used.

It has been shown that the interaction with both the laptop structure (screen and keyboard) and with the user have a strong effect on the radiation performance. Therefore, for proper evaluation of the in-use antenna performance the scenario constituents (IFA, PCMCIA card, laptop and user) have to be jointly taken into account as a whole. The laptop structure causes antenna detuning and modifies the far-field radiation pattern. Further changes in far-field pattern are caused by the presence of the user: blocking up to $15 \mathrm{~dB}$ towards the torso direction and blocking up to $10 \mathrm{~dB}$ of upward radiation by the wrist shadowing. The antenna radiation efficiency depends on the relative location of the user hand and the PCMCIA card and can drop down by over $50 \%$ when the card is below the wrist. The SAR distribution also depends on antenna location, however, even for the worst case, the peak SAR levels are much lower than the defined safety limits for an antenna output power of $10-100 \mathrm{~mW}$.

It is worth to mention that, although only simulation results are presented in this paper, the models used have been validated by experimental results in other very similar problems [1], [2], [8].
The results presented for the simplified scenarios encouraged the authors to perform a deeper analysis, which in future will consider the following factors: (i) use of other antenna types including internal antennas, (ii) study of other antenna locations, (iii) inclusion of the supporting table top in the model, (iv) a more realistic laptop casing, (v) a human model in non-typing position and (vi) a more elaborated inhomogeneous human model.

\section{Acknowledgements}

Jerzy Guterman, António A. Moreira and Custódio Peixeiro acknowledge the financial support of ACE Network of Excellence and the Portuguese Research Council (Fundação para a Ciência e a Tecnologia).

\section{References}

[1] GUTERMAN, J., RAHMAT-SAMII, Y., MOREIRA, A. A., PEIXEIRO, C. Radiation from commercially viable antennas for PCMCIA cards housed in laptops. In Proc. IST Mobile and Wireless Communications Summit. Budapest (Hungary), 2007.

[2] GUTERMAN, J., RAHMAT-SAMII, Y., MOREIRA, A. A., PEIXEIRO, C. Radiation pattern of a $2.4 / 5.2 \mathrm{GHz}$ laptop internal antenna: near field spherical range measurements and full wave analysis. In Proc. International Workshop on Antenna Technology IWAT. Cambridge (United Kingdom), 2007.

[3] JENSEN, M. A., RAHMAT-SAMII, Y. EM interaction of handset antennas and a human in personal communications. Proceedings of the IEEE, 1995. vol. 83, no. 1, p. 7-17.

[4] WANG, J., FUJIWARA, O. EM Interaction between a $5 \mathrm{GHz}$ band antenna mounted PC and a realistic human body model. IEICE Transaction on Communications, 2005, vol. E88-B, no.6, p. 2604 to 2608.

[5] SORAS, C., KARABOIKIS, M., TSACHTSIRIS, G., MAKIOS, V. Analysis and design of an inverted-F antenna printed on a PCMCIA card for the $2.4 \mathrm{GHz}$ ISM band. IEEE Antenna and Propagation Magazine, 2002, vol. 44, no. 1, p. 37-44.

[6] LiU, D., GAUCHER, B. P., FLinT, E. B., STUDWELL, T. W., USUI, H., BEUKEMA, T. J. Developing integrated antenna subsystems for laptop computers. IBM Journal of Research and Development, 2003, vol. 47, no. 2/3, p. 355-367.

[7] CENELEC, European Spec. ES 59005, Considerations for the evaluation of human exposure to electromagnetic fields (EMFs) from mobile telecommunication equipment (MTE) in the frequency range from $30 \mathrm{MHz}-6 \mathrm{GHz}$, Ref. ${ }^{\circ}$ ES 59005, 1998.

[8] GUTERMAN, J., PEIXEIRO, C., MOREIRA, A. A. Omnidirectional wrapped microstrip antenna: concept, integration and applications. Frequenz, 2007, vol. 61, no. 3-4, p. 78-83.

\section{About Authors}

Jerzy GUTERMAN received the B.S. and the M.S. degrees from Warsaw University of Technology, Poland in 2002 and 2004, respectively. Currently he is with Instituto de Telecomunicações, Instituto Superior Técnico (IST), Universidade Técnica de Lisboa, Portugal, where he is 
pursuing the Ph.D. degree on small and multi-band antennas, antennas for laptops, electromagnetic human interactions and MIMO antennas. From 2006 to 2007 he was Visiting Researcher at Antenna Research, Analysis, and Measurement Laboratory (ARAM), University of California, Los Angeles (UCLA) under supervision of Professor Yahya Rahmat-Samii. Jerzy Guterman has authored and co-authored one book chapter and over 30 technical journal articles and conference papers. He was awarded the 1st EuMA Microwave Prize at the 15th IEEE International Conference on Microwaves MIKON 2004, Poland and the Best Student Paper Prize at the 6th Conference on Telecommunications - ConfTele 2007, Portugal.

António A. MOREIRA received his Ph.D. degrees in electrical engineering from Instituto Superior Técnico (IST), Universidade Técnica de Lisboa, Portugal, in 1984. In 1989 he became an Associate Professor at the Electrical Engineering and Computers Department of IST. Since then he has been responsible for Antennas and Radar Systems courses. He also runs Telecommunications and Radar courses in the Portuguese Navy School. He is a researcher at Instituto de Telecomunicações, Lisbon, with his work focused in Antennas for Wireless Communications. In recent years he has co-authored several journal and conferences papers in his current research topic of antennas for laptops including antenna integration issues, MIMO enabled laptops and electromagnetic human interaction.

Custódio PEIXEIRO was born in Évora, Portugal in 1956. He received the graduation, master and doctor degrees in electrical and computer engineering from Instituto Superior Técnico (IST), Technical University of Lisbon, in 1980, 1985 and 1993, respectively. He has been teaching in the Department of Electrical and Computer Engineering since 1980 where he is now Assistant Professor. He is also a researcher of Instituto de Telecomunicações. His present research interests are focused in microstrip antennas and circuits for applications in mobile terminals (handsets, PDAs and laptop computers).

Yahya RAHMAT-SAMII received the M.S. and Ph.D. degrees in electrical engineering from the University of Illinois, Urbana-Champaign.

$\mathrm{He}$ is a Distinguished Professor and past Chairman of the Electrical Engineering Department, University of California, Los Angeles (UCLA). He was a Senior Research Scientist with the National Aeronautics and Space Administration (NASA) Jet Propulsion Laboratory (JPL), California Institute of Technology, prior to joining UCLA in 1989. In summer 1986, he was a Guest Professor with the Technical University of Denmark. He has also been a Consultant to numerous aerospace companies. He has been Editor and Guest Editor of numerous technical journals and books. He has authored and coauthored more than 660 technical journal and conference papers and has written 20 book chapters. He is a coauthor of Implanted Antennas in Medical Wireless Communications (Morgan\&Claypool, 2006), Electromagnetic Optimization by Genetic Algorithms (New York: Wiley, 1999), and Impedance Boundary Conditions in Electromagnetics (New York: Taylor \& Francis, 1995). He has received several patents. He has had pioneering research contributions in diverse areas of electromagnetics, antennas, measurement and diagnostics techniques, numerical and asymptotic methods, satellite and personal communications, human/antenna interactions, frequency selective surfaces, electromagnetic bandgap structures, applications of the genetic algorithms and particle swarm optimization.

Dr. Rahmat-Samii is a Fellow of the Institute of Advances in Engineering (IAE) and a member of Commissions A, B, $\mathrm{J}$, and $\mathrm{K}$ of USNC/URSI, the Antenna Measurement Techniques Association (AMTA), Sigma Xi, Eta Kappa Nu, and the Electromagnetics Academy. He was Vice-President and President of the IEEE Antennas and Propagation Society in 1994 and 1995, respectively. He was an IEEE AP-S Distinguished Lecturer. He was a member of the IEEE Strategic Planning and Review Committee (SPARC). He was the IEEE AP-S Los Angeles Chapter Chairman (1987-1989); his chapter won the best chapter awards in two consecutive years. He is listed in Who's Who in America, Who's Who in Frontiers of Science and Technology, and Who's Who in Engineering. He designed the IEEE AP-S logo displayed on all IEEE AP-S publications. He was a Director and Vice President of AMTA for three years. He has been Chairman and Cochairman of several national and international symposia. He was a member of the University of California at Los Angeles (UCLA) Graduate Council for three years. He has received numerous NASA and JPL Certificates of Recognition. In 1984, he received the Henry Booker Award from URSI. Since 1987, he has been designated every three years as one of the Academy of Science's Research Council Representatives to the URSI General Assemblies held in various parts of the world. In 1992 and 1995, he received the Best Application Paper Prize Award (Wheeler Award) for papers published in 1991 and 1993 IEEE Transactions on Antennas and Propagation. In 1999, he received the University of Illinois ECE Distinguished Alumni Award. In 2000, he received the IEEE Third Millennium Medal and the AMTA Distinguished Achievement Award. In 2001, he received an Honorary Doctorate in physics from the University of Santiago de Compostela, Spain. In 2001, he became a Foreign Member of the Royal Flemish Academy of Belgium for Science and the Arts. In 2002, he received the Technical Excellence Award from JPL. He received the 2005 URSI Booker Gold Medal presented at the URSI General Assembly. 